\title{
Role of Factor VIII-von Willebrand Factor and Fibronectin in the Interaction of Platelets in Flowing Blood with Monomeric and Fibrillar Human Collagen Types I and III
}

Wim P. M. Houdijk, Kjell S. Sakariassen, Patricia F. E. M. Nievelstein, and Jan J. Sixma

Department of Haematology, University Hospital Utrecht, The Netherlands

\section{Abstract}

Platelet adhesion to monomeric collagen types I and III, which were purified from human umbilical arteries, was studied in a perfusion chamber under well defined flow conditions. For this purpose, glass coverslips were coated with $20-30 \mu \mathrm{g} / \mathrm{cm}^{2}$ of collagen types I and III by spraying a solution of these collagens with a retouching air brush. Platelet deposition increased with the time of perfusion. Adhesion to both collagen types was similar in the first $3 \mathrm{~min}$, but increased platelet deposition occurred on collagen type III after $3 \mathrm{~min}$ due to thrombus formation. Adhesion at a shear rate of $800 \mathrm{~s}^{-1}$ was strongly impaired with plasma of a patient with von Willebrand's disease or with fibronectin-free plasma. Addition of purified fibronectin to fibronectin-free plasma restored adhesion to the level obtained with normal plasma. Platelet deposition in normal plasma increased with increasing shear rates. Platelet deposition in VWD-plasma was normal at $490 \mathrm{~s}^{-1}$, but there was no increase at higher shear rates. Platelet deposition in fibronectin-free plasma was diminished at all shear rates studied from 490 to $1,300 \mathrm{~s}^{-1}$.

Perfusion with a human albumin solution (HAS) to which purified Factor VIII-von Willebrand factor complex (FVIIIVWF) and fibronectin had been added gave similar platelet deposition as with normal plasma. Preincubation of collagen with FVIII-VWF and perfusion with HAS containing fibronectin, or, conversely, preincubation with fibronectin and perfusion with HAS containing FVIII-VWF, also resulted in adhesion similar to that observed in normal plasma. Similar adhesion was also observed after preincubation with both FVIII-VWF and fibronectin and subsequent perfusion with HAS alone. Sequential preincubations with first FVIII-VWF and then fibronectin, or with first fibronectin and then FVIII-VWF followed by perfusion with HAS, also gave a similar adhesion as observed with normal plasma.

These data indicate that platelet adhesion to monomeric collagen types I and III is dependent on both FVIII-VWF and fibronectin. FVIII-VWF is only required at relatively high shear rates; fibronectin also at relatively low shear rates. Their

Part of this work was presented at the IXth International Congress on Thrombosis and Haemostasis, Stockholm, Sweden, 1983, and has been published in abstract form in Thromb. Haemostasis, 50:1276, 1983 (Abstr.).

Address correspondence to Dr. Houdijk.

Received for publication 14 November 1983 and in revised form 14 September 1984.

J. Clin. Invest.

(C) The American Society for Clinical Investigation, Inc.

0021-9738/85/02/0531/10 \$1.00

Volume 75, February 1985, 531-540 complementary role in platelet adhesion suggests separate binding sites for FVIII-VWF and fibronectin on collagen.

Platelet deposition on preformed fibrils of collagen types I and III was also studied. Initial adhesion expressed as percentage surface coverage was similar to that found with monomeric collagen, but thrombus formation was much enhanced. Adhesion on fibrillar collagen at $800 \mathrm{~s}^{-1}$ was impaired in VWD-plasma and fibronectin-free plasma, and was restored by addition of purified fibronectin to fibronectin-free plasma. When perfusions were performed with HAS, only addition of FVIII-VWF was required for optimal adhesion to fibrillar collagen; addition of fibronectin had no effect. These data are in contrast to the studies with monomeric collagens described above, in which the addition of both FVIII-VWF and fibronectin was required. These data are also in contrast to the observation that in plasma both FVIII-VWF and fibronectin are required for optimal adhesion to fibrillar collagen.

\section{Introduction}

Adhesion of blood platelets to perivascular collagen is one of the first steps in the formation of a hemostatic plug (1). Direct observations of hemostatic plug formation in bleeding time skin wounds of patients with von Willebrand's disease (VWD) ${ }^{1}$ indicated an abnormality of this step (2). The role of Factor VIII-von Willebrand factor complex (FVIII-VWF) in platelet adhesion was further substantiated in perfusion studies in an annular perfusion chamber in which abnormal adhesion of platelets to subendothelium of a rabbit aorta, human renal, or umbilical artery was found with blood deficient in FVIII-VWF (3-6). Perfusion studies in which collagen fibrils were exposed to blood of a patient with VWD indicated that FVIII-VWF was directly implicated in the adhesion of blood platelets to collagen (7), but more detailed studies were not yet performed.

As a second protein involved in platelet adhesion or spreading to collagen, fibronectin has been proposed (8-10). Its role has been disputed by others $(11,12)$, and no direct evidence for a major role of fibronectin in the adhesion of blood platelets to collagen is currently available.

We have studied the platelet deposition on collagen purified from human umbilical arteries under standardized flow conditions. We present evidence that FVIII-VWF as well as fibronectin are required for optimal platelet interaction.

\section{Methods}

Isolation of collagens. Collagen types I and III were isolated from human umbilical arteries by pepsin digestion (13). Separation of the collagen types was achieved by the method of ChandraRajan (14).

1. Abbreviations used in this paper: FVIII R:Ag, Factor VIII related antigen; FVIII R:RCF, Factor VIII related ristocetin cofactor activity; FVIII-VWF, Factor VIII-von Willebrand factor complex; HAS, human albumin solution; VWD, von Willebrand's disease. 
Purity and identity were assessed by electrophoresis on reduced and nonreduced 5\% SDS-polyacrylamide gels. Only collagen $\alpha, \beta$, and $\gamma$ bands were observed when $10 \mu \mathrm{g}$ of protein was applied to the gel. Collagen $\alpha_{1}$ (I) and $\alpha_{2}$ (I) bands (ratio 2:1) had apparent molecular weights of 129,000 and 115,000 , respectively, using globular protein molecular weight standards; $\alpha_{1}$ (III) co-migrated with $\alpha_{1}$ (I) under reducing conditions. The collagen type III preparation was contaminated with $<5 \%$ collagen type I as assessed by densitometric scanning.

Preparation of collagen fibrils. Collagen was dissolved at $1 \mathrm{mg} / \mathrm{ml}$ in $50 \mathrm{mM}$ acetic acid and dialyzed against $20 \mathrm{mM} \mathrm{Na}_{2} \mathrm{HPO}_{4}$ at $4^{\circ} \mathrm{C}$ for $48 \mathrm{~h}$ to reconstitute native type fibrils (15). The completion of fibril formation was checked turbidimetrically in a spectrofotometer at $313 \mathrm{~nm}(16)$. The collagen fibrils were collected by centrifugation (30 min, $30,000 \mathrm{~g}, 4^{\circ} \mathrm{C}$ ) and resuspended in $20 \mathrm{mM} \mathrm{Na} \mathrm{HPO}_{4}$. The collagen concentration in the fibrillar suspension was determined by hydroxyproline analysis.

Preparation of fibronectin-free plasma and purification of fibronectin. Fibronectin was isolated from normal human plasma by affinity chromatography on gelatin-Sepharose (17). Gelatin-Sepharose 4B was prepared by coupling gelatin (E. Merck, AG, Darmstadt, Federal Republic of Germany) to CNBr-activated Sepharose 4B (Pharmacia Fine Chemicals AB, Uppsala, Sweden), according to the manufacturer.

Plasma $(200 \mathrm{ml})$ was passed over the gelatin-Sepharose column $(2.6 \times 16 \mathrm{~cm}$, equilibrated with $0.05 \mathrm{M}$ Tris- $\mathrm{HCl}, \mathrm{pH} 7.4)$ and collected; the first and last fractions were discarded to minimize dilution. This fibronectin-depleted plasma contained no detectable $(<3 \mu \mathrm{g} / \mathrm{ml})$ fibronectin in an electroimmunoassay (18) with rabbit anti-human fibronectin antiserum (Cappel Laboratories, Cochranville, PA) and purified fibronectin as a standard. The level of Factor VIII related antigen (FVIII R:Ag) was unchanged, while Factor VIII related ristocetin cofactor activity (FVIII R:RCF) decreased a little, but was in the range of $0.65-$ $0.80 \mathrm{U} / \mathrm{ml}$ after passage over the gelatin-Sepharose column. The fibronectin-free plasma was stored frozen at $-70^{\circ} \mathrm{C}$.

For the purification of fibronectin, the gelatin-column was washed

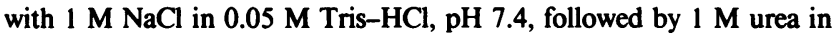
the same Tris-buffer. Fibronectin was eluted with $6 \mathrm{M}$ urea, $0.1 \mathrm{M}$ citric acid, pH 4.7 (19). The buffers contained $0.1 \mathrm{mM}$ phenylmethylsulfonylfluoride, $1 \mathrm{mM}$ benzamidine, $5 \mathrm{mM}$-aminocaproic acid, 10 $\mathrm{mM}$ EDTA, and $0.02 \%(\mathrm{wt} / \mathrm{vol})$ sodium azide. The pooled peak fractions were dialyzed at $4^{\circ} \mathrm{C}$ against Krebs-Ringer buffer $(4 \mathrm{mM}$ $\mathrm{KCl}, 107 \mathrm{mM} \mathrm{NaCl}, 20 \mathrm{mM} \mathrm{NaHCO}{ }_{3}, 2 \mathrm{mM} \mathrm{Na}_{2} \mathrm{SO}_{4}, \mathrm{pH}$ 7.4) supplemented with $19 \mathrm{mM}$ trisodium citrate and $2.5 \mathrm{mM} \mathrm{CaCl}_{2}$.

Fibronectin was also purified under nondenaturing conditions (20). The gelatin-sepharose column was first washed with $1 \mathrm{M} \mathrm{NaCl}$ in 0.05 $\mathrm{M}$ Tris- $\mathrm{HCl}, \mathrm{pH} 7.4$, and then with $0.2 \mathrm{M}$ arginine in the same buffer. Finally fibronectin was eluted with $1 \mathrm{M}$ arginine in $0.05 \mathrm{M}$ Tris- $\mathrm{HCl}$, pH 7.4.

The fibronectin solutions were stored at $4^{\circ} \mathrm{C}$ and used for experiments within 1 wk. Electrophoresis on 5\% SDS-polyacrylamide gel after reduction with 2-mercaptoethanol showed $>95 \%$ homogeneity. This fibronectin preparation contained $<1.0 \mathrm{mU}$ FVIII R:Ag/mg protein as determined with an enzyme-linked immunosorbent assay (21). The fibronectin preparations were also analyzed on $5 \%$ nonreduced gels. Zone I (450,000-mol wt dimers) and zone II (190,000-235,000 mol wt) fibronectin bands as well as high molecular weight multimers were present (22). Densitometric scanning showed $77 \%$ zone I, 18\% zone II, and 5\% multimers in a fibronectin preparation purified in the presence of urea. A preparation purified in the presence of arginine showed $86 \%$ zone I, $9 \%$ zone II, and $5 \%$ multimers.

Purification of FVIII-VWF. FVIII-VWF was purified from human cryoprecipitate by a modification of the method described by Van Mourik and Mochtar (23). Cryoprecipitate was dissolved in Michaelis buffer (28.5 mM sodium acetate, $28.5 \mathrm{mM}$ sodiumbarbital, and 116 $\mathrm{mM}$ sodium chloride, $\mathrm{pH}$ 7.35) that contained $5 \mathrm{mM}$ trisodium citrate, $10 \mathrm{mM}$ benzamidine, $10 \mathrm{mM}$-aminocaproic acid, and $10 \mathrm{mM}$ EDTA. The solution was applied to a column of Sepharose CL-4B (Pharmacia Fine Chemicals AB, Uppsala, Sweden). Elution was carried out with dextran-barbital buffer (17.2 mM barbital, $2.8 \mathrm{mM}$ sodiumbarbital, $125 \mathrm{mM} \mathrm{NaCl}$, and $3.3 \%$ [wt/vol] dextran, mean molecular weight of 40,000 ) that contained $5 \mathrm{mM}$ trisodium citrate, $10 \mathrm{mM}$-aminocaproic acid, and $1 \mathrm{mM}$ benzamidine, $\mathrm{pH}$ 7.0.

The FVIII-VWF protein in the void volume fractions was precipi-

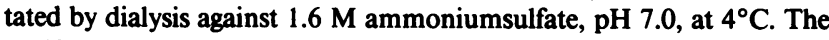
purified protein has been characterized extensively before (24). Before use, the precipitated protein was dissolved in Krebs-Ringer buffer, $\mathrm{pH}$ 7.35 , with $19 \mathrm{mM}$ citrate, $2.5 \mathrm{mM} \mathrm{CaCl}$, and $4 \%$ (wt/vol) human albumin (Behringwerke AG, Marburg, Federal Republic of Germany). Fibronectin was not detectable $(<3 \mu \mathrm{g} / \mathrm{ml})$ using an electroimmunoassay (18).

Perfusion chamber. For studying platelet interaction with purified components under standardized flow conditions, a rectangular perfusion chamber was constructed. The construction of this parallel-plate perfusion chamber and its rheological properties had been described elsewhere (25). A glass microscope coverslip was coated with the component of interest and inserted into the perfusion chamber. Wall shear rates were calculated with the formula used by Muggli (26).

Coating coverslips with collagen. Glass microscope coverslips $(18 \times 18 \mathrm{~mm}$, Menzelgläser, Braunschweig, Federal Republic of Germany) were soaked overnight in $80 \%$ ethanol and rinsed with deionized water. Collagen $(1 \mathrm{mg} / \mathrm{ml}$ in $50 \mathrm{mM}$ acetic acid) was sprayed onto the glass coverslips with a retouching airbrush (Badger model 100 IL, Badger Air-Brush Co., Franklin Park, IL), connected to a nitrogen cylinder operating at a pressure of one atmosphere (26). The fine collagen droplets dried instantly on the glass surface at room temperature; $83 \pm 9 \%$ (mean $\pm \mathrm{SD}, n=8$ ) of the applied amount of collagen was deposited on the glass surface, as determined by weighing the coverslips with a micro-balance before and after spraying.

Staining of the coated coverslips with Coomassie Brilliant Blue showed a uniform collagen distribution. The same coating was obtained when preformed collagen fibrils were sprayed. The spraying procedure could possibly denaturate the collagen on the glass surface. The same spraying technique was previously used by Muggli et al. (26) and resulted in a reproducible platelet deposition.

Preincubation of collagen-coated coverslips with FVIII-VWF and/ or fibronectin. Four coverslips coated with collagen type I or type III $\left(30 \mu \mathrm{g} / \mathrm{cm}^{2}\right)$ were placed in a plastic dish filled with $2 \mathrm{ml} \mathrm{Krebs-Ringer}$ buffer, pH 7.35 (with $2.5 \mathrm{mM} \mathrm{CaCl} 2$ and $19 \mathrm{mM}$ citrate), that contained either FVIII-VWF (1 U FVIIIR:RCF/ml) or fibronectin (200 $\mu \mathrm{g} / \mathrm{ml}$ ) or both. As a control, collagen was incubated with buffer only. After $30 \mathrm{~min}$ at room temperature the protein solution was removed. The coverslips were rinsed once with Krebs-Ringer buffer (with $\mathrm{CaCl}_{2}$ and citrate) and kept under buffer, to prevent drying and denaturation, until perfusion.

Preparation of perfusates. Blood from normal donors was anticoagulated with $1 / 10$ vol $110 \mathrm{mM}$ trisodium citrate. Platelets were obtained by centrifugation $\left(10 \mathrm{~min}, 200 \mathrm{~g}, 20^{\circ} \mathrm{C}\right.$ ) and washed in Krebs-Ringer as previously described (5). After the first washing, platelets were incubated with $10 \mu \mathrm{M}$ aspirin (5) and labeled with "'In (27) by adding $10 \mu \mathrm{Ci} / \mathrm{ml}$ "'In-oxinate (Byk-Mallinckrodt, C.I.L., B.V., Petten, The Netherlands). The incubation with aspirin was to prevent plateletplatelet interaction and has been reported to have no effect on adherence $(26,28)$. Platelets were resuspended in plasma or a $4 \%$ (wt/ vol) human albumin solution (HAS) in Krebs-Ringer buffer, $\mathrm{pH} 7.35$, that contained $19 \mathrm{mM}$ citrate, $2.5 \mathrm{mM} \mathrm{CaCl}_{2}$, and $5 \mathrm{mM} \alpha$-D-glucose (5).

Plasma was either normal plasma or plasma from classic VWD patients (FVIII R:RCF $<0.06 \mathrm{U} / \mathrm{ml}$ ) or fibronectin-free plasma. As VWD plasma substitute, we also used the supernatant plasma remaining after cryoprecipitation (cryosupernatant plasma, FVIII R:RCF $<0.06$ $\mathrm{U} / \mathrm{ml})$. The perfusate $(15 \mathrm{ml})$ was reconstituted by adding washed red cells to the resuspended platelets (hematocrit, 0.4; platelet count, 114 $\times 10^{6} / \mathrm{ml}$, final concentration).

Perfusion. The perfusates were prewarmed at $37^{\circ} \mathrm{C}$ for $5 \mathrm{~min}$ and recirculated through the perfusion chamber under a nonpulsatile steady 
flow (29). The whole system was maintained at $37^{\circ} \mathrm{C}$ in a waterbath. The chamber was prefilled with prewarmed $0.2 \mathrm{M}$ Tris- $\mathrm{HCl}, \mathrm{pH} 7.4$. After perfusion, the system was rinsed with $25 \mathrm{ml}$ of $0.2 \mathrm{M}$ Tris-buffer, pH 7.4; the coverslip was removed, rinsed once with buffer, and the platelet deposition was determined by counting ${ }^{11}$ In-radioactivity in a gamma counter. For morphometric analysis, the coverslips were fixed and stained as previously described (25). The platelet coverage on collagen was evaluated by light microscopy at 1,000 times magnification with an eye piece micrometer (E. Leitz, GmbH, Wetzlar, Federal Republic of Germany) in the ocular (25). About 1,000 intersection points at $10-\mu \mathrm{m}$ intervals along a line perpendicular to the flow were scored for the presence or absence of platelets. The intersections with platelets were given as percentage of total and expressed as percentage surface coverage. Evaluations were also performed with the light microscope connected to an image analyzer (Quantimet 720, Imanco, Royston, United Kingdom). For every coverslip, 10 fields selected at random were evaluated at 1,000 times magnification. Each field $(0.028$ $\mathrm{mm}^{2}$ ) consisted of 500,000 image points. Similar results were obtained with both evaluation methods.

Other assays. Protein concentration was determined by the dyebinding method of Bradford (30). Collagen was determined by hydrolysis of a sample in $6 \mathrm{~N} \mathrm{HCl}$ during $3 \mathrm{~h}$ at $130^{\circ} \mathrm{C}$ and subsequent determination of free hydroxyproline residues (31). The amount of collagen was obtained by multiplying the amount of hydroxyproline by 7.64 (32). The concentration of FVIII-VWF was determined with the ristocetin cofactor assay by agglutination of formalin fixed normal platelets in a Payton dual channel aggregometer $(33,34)$. The concentration was expressed in units per milliliter, in which one unit is defined as the activity of $1 \mathrm{ml}$ of a pool of frozen citrated plasma from 40 healthy donors. SDS-polyacrylamide gel electrophoresis was performed on 5\% gels with the discontinuous system described by Laemmli (35).

Statistical analysis. Statistical significance of differences between means was evaluated with $t$ test.

\section{Results}

\section{Platelet deposition on monomeric collagen}

Time and concentration dependence. Platelet deposition on nonfibrillar monomeric collagen type I and type III increased with the duration of the perfusion (Fig. 1). During the first 3 min, platelet deposition was more or less similar on both collagen types, but increased platelet deposition was seen on collagen type III after $3 \mathrm{~min}$. Comparison of surface coverage data and ${ }^{111}$ Indium counting indicated that thrombus formation was minimal in the first $3 \mathrm{~min}$ (25). The increased platelet deposition on collagen type III after $3 \mathrm{~min}$ was probably due

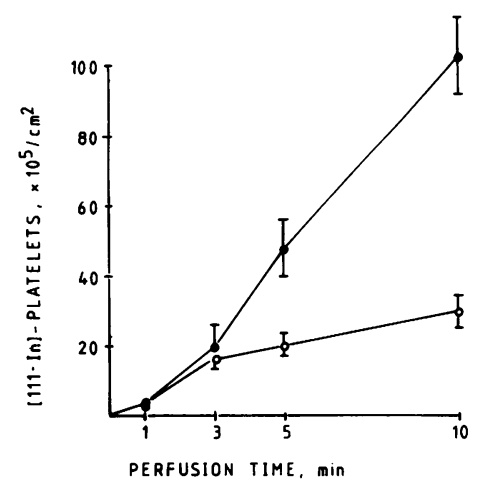

Figure 1. Time course of platelet deposition on collagen type I ([o]; $30 \mu \mathrm{g} / \mathrm{cm}^{2}$ )

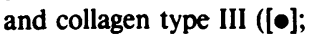
$\left.20 \mu \mathrm{g} / \mathrm{cm}^{2}\right)$. The collagens were applied in nonfibrillar form. Perfusions were performed at a shear rate of $800 \mathrm{~s}^{-1}$ with normal plasma. The platelet deposition, representing the absolute number of platelets on the surface, was determined from the ${ }^{11 '}$ In-radioactivity. Values represent mean $\pm \operatorname{SEM}(n=4-8)$. to thrombus formation. For these reasons, a standard perfusion time of $3 \mathrm{~min}$ was chosen.

Studies on the dependence of adhesion on the quantity of collagen types I and III (nonfibrillar) showed an optimal platelet deposition at 30 and $20 \mu \mathrm{g} / \mathrm{cm}^{2}$, respectively (Fig. 2). At higher amounts of collagen, the platelet deposition decreased slightly, though was not statistically significant.

Role of plasma proteins. The role of plasma proteins in platelet deposition on monomeric collagen types I and III was studied by comparing the platelet deposition in HAS, in normal plasma, and in plasma lacking FVIII-VWF (VWDplasma, cryosupernatant plasma) or fibronectin. The results in Table I show that platelet deposition with plasmas lacking either FVIII-VWF or fibronectin was minimal, and in the same range as found with HAS.

When the concentration of fibronectin was varied by adding different amounts of purified fibronectin to fibronectinfree plasma, the platelet deposition was similar to that in normal plasma at $200 \mu \mathrm{g} / \mathrm{ml}$ (Fig. 3). The fibronectin preparation which we used here was purified under denaturating conditions using $6 \mathrm{M}$ urea (see Methods). Mosher and Johnson (36) previously reported that exposure of concentrated fibronectin solutions to denaturating agents produced disulfidebonded multimers which could have a higher biological activity. We therefore also tested the effect of fibronectin purified under nondenaturating conditions with $1 \mathrm{M}$ arginine (see Methods). With both fibronectin preparations added at 200 and $500 \mu \mathrm{g} /$ $\mathrm{ml}$, platelet deposition was similar to that observed in normal plasma (Table II).

Shear rate dependence. The effect of FVIII-VWF on platelet adhesion to subendothelium was reported to be more pronounced at higher wall shear rates (38). We therefore studied the effect of various wall shear rates on platelet deposition on collagen (Fig. 4). In normal plasma platelet deposition on monomeric collagen type III increased with the shear rate. At a wall shear rate of $490 \mathrm{~s}^{-1}$, platelet deposition in VWDplasma was the same as in normal plasma, but no increase occurred at higher shear rates, whereas in normal plasma, platelet deposition became almost three times as high at higher shear rates. Fibronectin-free plasma showed a decreased platelet deposition at all wall shear rates which were tested, and also at the lowest shear rate of $490 \mathrm{~s}^{-1}(P<0.005)$.

Preincubation of collagen with FVIII-VWF and/or fibronectin. Monomeric collagen type III was preincubated with FVIII-VWF $(1 \mathrm{U} / \mathrm{ml})$ or fibronectin $(200 \mu \mathrm{g} / \mathrm{ml})$ or buffer

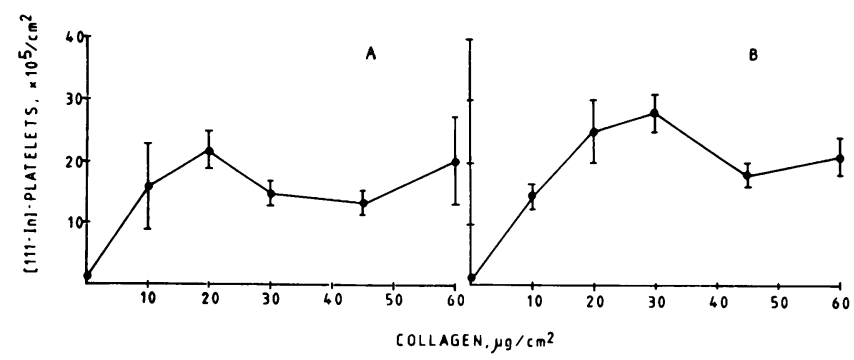

Figure 2. Platelet deposition on collagen type III $(A, n=4)$ and collagen type I ( $B, n=4-13)$ with various (nonfibrillar) amounts of collagen on the surface. Perfusions were carried out with normal plasma for $3 \mathrm{~min}$ at $800 \mathrm{~s}^{-1}$. Values are mean \pm SEM. 
Table I. Platelet Deposition on Collagen; Influence of Plasma Proteins

\begin{tabular}{lcl}
\hline & \multicolumn{2}{c}{ Platelet deposition } \\
\cline { 2 - 3 } Perfusate & Collagen type I & Collagen type III \\
\hline Normal plasma & $16.5 \pm 2.6(8)$ & $17.4 \pm 2.8(9)$ \\
Cryosupernatant plasma & $3.0 \pm 0.8(7)^{*}$ & ND \\
VWD-plasma & $6.3 \pm 0.9(4) \ddagger$ & $4.5 \pm 1.0(6) \S$ \\
Fibronectin-free plasma & $1.7 \pm 0.3(13)^{*}$ & $3.3 \pm 1.4(6) \S$ \\
HAS & $2.4 \pm 0.3(10)^{*}$ & $1.9 \pm 0.3(6)^{*}$
\end{tabular}

Platelet deposition on collagen type I and type III. Collagen was applied in a soluble form at a concentration of $30 \mu \mathrm{g} / \mathrm{cm}^{2}$. Perfusions were performed for 3 min at a wall shear rate of $800 \mathrm{~s}^{-1}$ with the indicated plasmas. Values are the mean $\pm S E M$; the number of determinations are indicated in parentheses. $P$-values are compared with normal plasma.

${ }^{*} P<0.001$.

$\ddagger P<0.025$.

$\S P<0.005$.

$\mathrm{ND}$, not determined.

only. Subsequently, perfusions were performed with HAS to which purified FVIII-VWF or fibronectin or both were added (Table III). When collagen was preincubated with buffer, addition of FVIII-VWF and fibronectin to the perfusate with HAS restored the platelet deposition to the level obtained with normal plasma. Addition of FVIII-VWF or fibronectin alone resulted in only a slight increase in platelet deposition as compared with perfusion with HAS.

Preincubation of collagen with FVIII-VWF and perfusion with HAS containing fibronectin gave a platelet deposition as in normal plasma. Conversely, preincubation with fibronectin and perfusion with HAS containing FVIII-VWF resulted also in a platelet deposition as obtained in normal plasma.

Sequential preincubations were then performed in which collagen type III was first preincubated with fibronectin and then with FVIII-VWF, or the reverse. Collagen was also preincubated with both proteins together. Subsequently, perfusions were performed with HAS. The results are also shown in Table III. The platelet deposition found when collagen was preincubated with first fibronectin and then FVIII-VWF was similar to the deposition found when both proteins were present in HAS or to the deposition after perfusion with normal plasma. Platelet deposition after preincubation with first FVIII-VWF and then fibronectin was slightly lower than with normal plasma, but significantly higher than preincubation

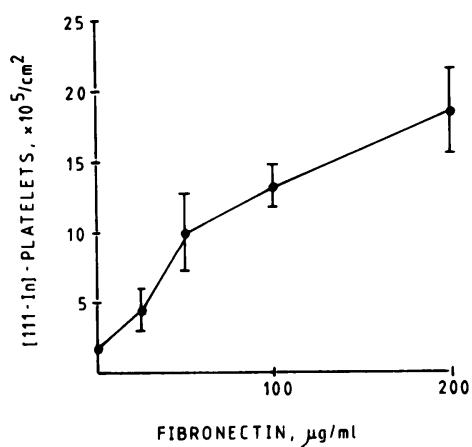

Figure 3. Effect of fibronectin concentration on platelet deposition on collagen type I (mean \pm SEM; $n$ = 4-13). Perfusions were performed with fibronectinfree plasma with different amounts of purified fibronectin added. Perfusion time, $3 \mathrm{~min}$; shear rate, 800 $\mathrm{s}^{-1}$. Collagen, $30 \mu \mathrm{g} / \mathrm{cm}^{2}$ (nonfibrillar).
Table II. Effect of Fibronectin Purification Procedure on Platelet Deposition on Collagen Type III

\begin{tabular}{lll}
\hline & \multicolumn{1}{c}{ Platelet deposition } \\
\cline { 2 - 3 } Perfusate & 11'In-platelets $\times 10^{5} / \mathrm{cm}^{2}$ \\
\hline Normal plasma & $36.1 \pm 9.9$ & \\
Fibronectin-free plasma & $7.6 \pm 1.5$ & \\
& $6 \mathrm{M}$ urea & $1 \mathrm{M}$ arginine \\
\cline { 2 - 3 } & & \\
Fibronectin-free plasma + fibronectin & & $39.1 \pm 4.1$ \\
$200 \mu \mathrm{g} / \mathrm{ml}$ & $39.3 \pm 9.0$ & $33.7 \pm 4.0$ \\
$500 \mu \mathrm{g} / \mathrm{ml}$ & $38.3 \pm 10.3$ &
\end{tabular}

Platelet deposition on collagen type III (nonfibrillar), $30 \mu \mathrm{g} / \mathrm{cm}^{2}$ (mean \pm SEM; $n=4$ ). Perfusions were performed for $3 \mathrm{~min}$ at a shear rate of $800 \mathrm{~s}^{-1}$ with normal plasma, fibronectin-free plasma, or fibronectin-free plasma containing 200 or $500 \mu \mathrm{g} / \mathrm{ml}$ purified fibronectin. Fibronectin was purified under either denaturating (6 M urea) or nondenaturating (1 $\mathrm{M}$ arginine) conditions as described under Methods.

with FVIII-VWF or fibronectin alone. Finally, preincubation with FVIII-VWF and fibronectin together followed by perfusion with HAS gave a platelet deposition as in normal plasma.

Similar experiments were also performed with monomeric collagen type I. Preincubation with fibronectin or FVIII-VWF alone followed by perfusion with HAS resulted in a low platelet deposition; however, when the preincubation was performed with both proteins together, a platelet deposition as in normal plasma was obtained (data not shown).

\section{Platelet deposition on fibrillar collagen}

Comparison with monomeric collagen. The deposition of blood platelets on fibrillar and nonfibrillar collagen types I and III were compared after 3 min perfusion with normal plasma at a wall shear rate of $800 \mathrm{~s}^{-1}$. The total platelet deposition was determined by ${ }^{111}$ Indium counting, and the percentage of the surface covered with platelets was evaluated by en face morphometrical estimation. The results are shown in Table IV. In a previous study on adherence of blood platelets to the subendothelium of human renal arteries, a good correlation was found between the percentage surface coverage and the number of deposited platelets in $10^{5} / \mathrm{cm}^{2}$ when a monolayer of platelets was present (6). Comparison of en face morphometry with radioactivity counting gives thus indirect information about platelet aggregate formation (25).

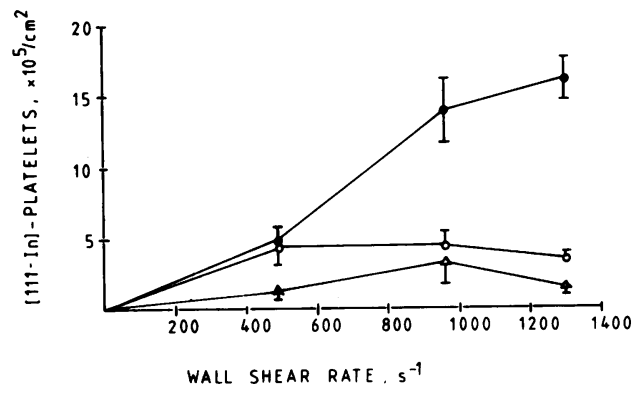

Figure 4. Platelet deposition on collagen type III (mean \pm SEM; $n=6-9$ ). Effect of shear rate. Perfusions were performed with NP $(\bullet)$, VWD-plasma (0), and fibronectin-free plasma $(\Delta)$. Perfusion time, $3 \mathrm{~min}$; collagen, $30 \mu \mathrm{g} / \mathrm{cm}^{2}$ (nonfibrillar). 
Table III. Platelet Deposition on Collagen Type III; Preincubation with FVIII-VWF and/or Fibronectin

\begin{tabular}{llc}
\hline & & Platelet deposition \\
\hline Preincubation & Perfusate & "'In-platelets $\times 10^{5} / \mathrm{cm}^{2}$ \\
\hline & Normal plasma & $14.7 \pm 2.9$ \\
& HAS & $1.9 \pm 0.3^{*}$ \\
& HAS + FVIII-VWF & $3.0 \pm 0.9^{*}$ \\
& HAS + FN & $3.0 \pm 0.4^{*}$ \\
FVIII-VWF & HAS + FN + FVIII-VWF & $12.0 \pm 2.3$ \\
& HAS & $4.4 \pm 0.9 \ddagger$ \\
& HAS + FVIII-VWF & $6.4 \pm 1.8 \S$ \\
FN & HAS + FN & $10.9 \pm 1.1$ \\
& HAS & $5.0 \pm 0.3 \ddagger$ \\
& HAS + FVIII-VWF & $15.3 \pm 3.3$ \\
FN + FVIII-VWF & HAS & $6.8 \pm 0.8^{*}$ \\
1 FN & & $14.5 \pm 2.8$ \\
2 FVIII-VWF & HAS & \\
1 FVIII-VWF & & $12.5 \pm 1.8$ \\
2 FN & HAS & \\
\hline
\end{tabular}

Collagen type III (nonfibrillar, $30 \mu \mathrm{g} / \mathrm{cm}^{2}$ ) was preincubated with FVIII-VWF (1 U/ml) and/or fibronectin $(200 \mu \mathrm{g} / \mathrm{ml})$ or buffer only for $30 \mathrm{~min}$ at room temperature. The last two experiments were sequential preincubation in which collagen was first preincubated with fibronectin, rinsed with buffer, and then preincubated with FVIIIVWF, or in reverse order. After the preincubations, perfusions were performed with platelets in HAS or in HAS supplemented with FVIII-VWF (1 U/ml) and/or fibronectin $(200 \mu \mathrm{g} / \mathrm{ml})$ for $3 \mathrm{~min}$ at $1,300 \mathrm{~s}^{-1}$.

Values represent means \pm S.E.M. $(n=6)$. FN, fibronectin.

$* P<0.005$.

$\dagger P<0.01$.

$\S P<0.05$, compared with perfusion with normal plasma.

For the nonfibrillar soluble collagen types I and III, the platelet deposition found by ${ }^{111}$ Indium counting corresponded reasonably well with the percentage surface coverage (Table

Table IV. Platelet Deposition on Fibrillar and Nonfibrillar Collagen Types I and III

\begin{tabular}{llr}
\hline Collagen type & '"'In-platelets $\times 10^{5} / \mathrm{cm}^{2}$ & \multicolumn{1}{l}{$\begin{array}{l}\text { \% Surface } \\
\text { coverage }\end{array}$} \\
\hline Collagen type I & $21.0 \pm 1.9(8)$ & $14.8 \pm 1.2(6)$ \\
Collagen type I (fibrillar) & $64.2 \pm 3.8(6)$ & $16.9 \pm 0.4(3)$ \\
Collagen type III & $10.6 \pm 0.9(6)$ & $9.6 \pm 1.1(6)$ \\
Collagen type III (fibrillar) & $73.1 \pm 3.9(4)$ & $20.7 \pm 1.3(3)$
\end{tabular}

Glass coverslips were sprayed with collagen type I or type III, which were applied in either soluble (in $50 \mathrm{mM}$ acetic acid) or fibrillar form (prepared by dialysis against $20 \mathrm{mM} \mathrm{Na}_{2} \mathrm{HPO}_{4}$, at $4^{\circ} \mathrm{C}$ for $48 \mathrm{~h}$ ). Collagen concentration was $30 \mu \mathrm{g} / \mathrm{cm}^{2}$, and perfusions were performed with platelets in normal plasma for $3 \mathrm{~min}$ at a wall shear rate of $800 \mathrm{~s}^{-1}$. The total platelet deposition was determined from "11'Inradioactivity and the percentage surface coverage was determined by en face morphometrical evaluation after fixation and staining, as described under methods. Values represent mean \pm SEM, with the number of experiments in parentheses.
IV). This indicates that hardly any thrombi were present. On fibrillar collagen, however, the total platelet deposition was much higher than the percentage surface coverage, which indicated the presence of thrombi. This was confirmed by light microscopy (Fig. 5). On the nonfibrillar collagens, only single platelets or small groups of single platelets were visible (Fig. 5, $A$ and $B$ ). On the fibrillar collagens, much larger platelet clumps were seen (Fig. 5, $C$ and $D$ ).

Time and concentration dependence. The platelet deposition on fibrillar collagen types I and III increased with the time of perfusion (Fig. 6). During the first $5 \mathrm{~min}$, the rate of platelet deposition was very similar on both collagen types. On collagen type I there was no increase in platelet deposition after $5 \mathrm{~min}$. On collagen type III, the platelet deposition still increased after $5 \mathrm{~min}$, but at a lower rate.

Studies of the dependence of platelet adhesion on the amount of collagen showed that the platelet deposition on fibrillar collagen type I and type III reached a similar plateau level at 10 and $20 \mu \mathrm{g} / \mathrm{cm}^{2}$, respectively (Fig. 7).

Role of plasma proteins. Platelet adhesion (i.e., initial attachment and spreading) to fibrillar collagen was evaluated as percentage surface coverage by en face morphometry. As with nonfibrillar collagen (Table I), the role of plasma proteins in platelet adhesion to fibrillar collagen was studied by comparing the adhesion in HAS, normal plasma, VWD-plasma, and fibronectin-free plasma.

The results in Table $\mathrm{V}$ show that with plasmas lacking either FVIII-VWF or fibronectin, platelet adhesion was strongly impaired towards the low level obtained with HAS. Platelet adhesion could be restored by adding purified fibronectin to fibronectin-free plasma.

Preincubation with FVIII-VWF and/or fibronectin. Analogous to the preincubation experiments with nonfibrillar collagen type III (Table III), we also performed these experiments with fibrillar collagen type III. The fibrillar collagen was preincubated with either FVIII-VWF or fibronectin or both. Subsequently perfusions were performed with platelets in HAS that contained either FVIII-VWF or fibronectin. The results are shown in Table VI. In contrast to nonfibrillar collagen type III, only FVIII-VWF, and not fibronectin, was required. The surface coverage was the same whether the perfusion was performed with normal plasma or with HAS containing FVIII-VWF. When fibrillar collagen was preincubated with FVIII-VWF, there was no requirement for FVIII-VWF or fibronectin in the perfusate, and perfusion with HAS alone resulted in surface coverage as obtained with normal plasma.

These results differ from those in Table $\mathrm{V}$, where platelet adhesion to fibrillar collagen type III was impaired in fibronectin-free plasma. The possibility exists that the reactivity of fibrillar collagen results in activation of the platelets and release of fibronectin from the $\alpha$-granules (37). In HAS, this released fibronectin could support adhesion, but couldn't support it in fibronectin-free plasma; this was possibly due to competition with other plasma proteins.

To further address this, we performed perfusions with fibronectin-free VWD-plasma, which is deficient in both FVIIIVWF and fibronectin. The results in Table VII show that in this plasma adhesion was negligible. Addition of FVIII-VWF or fibronectin alone did not restore the adhesion, but addition of both proteins resulted in adhesion similar to normal plasma. Thus, in the plasma milieu, both FVIII-VWF and fibronectin are clearly required to support adhesion to fibrillar collagen. 

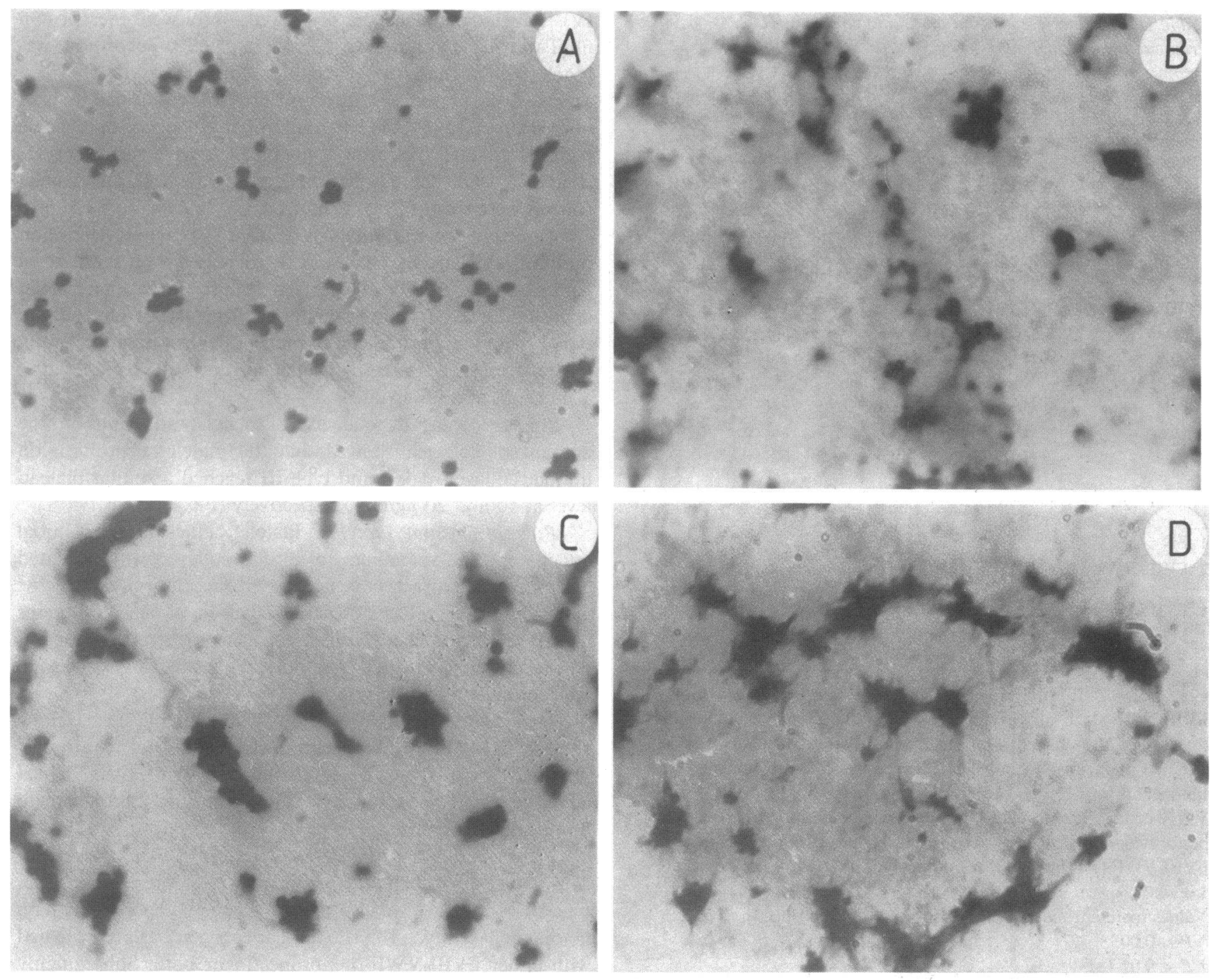

Figure 5. Morphology (en face) of platelet deposition on coverslips coated with fibrillar or nonfibrillar collagen types I and III $\left(30 \mu \mathrm{g} / \mathrm{cm}^{2}\right)$. Perfusions were performed with normal plasma for $3 \mathrm{~min}$ at a wall shear rate of $800 \mathrm{~s}^{-1}$. After perfusion the coverslips were fixed and stained as previously described (25). (A) Nonfibrillar collagen type I; $(B)$ nonfibrillar collagen type III; $(C)$ fibrillar collagen type I; and $(D)$ fibrillar collagen type III. $\times 1,000$.

\section{Discussion}

Platelet interaction with human collagen types I and III, purified from human umbilical arteries, was studied in a rectangular perfusion chamber under flow conditions as in small arteries. These collagen types were applied to glass coverslips in two forms by spraying either triple-helical soluble collagen monomers or preformed fibrils. Spraying resulted in a reproducible and uniform coating with a defined collagen density.

Drying the collagen on the surface may have resulted in denaturation. To avoid this, glass or other surfaces can be coated with collagen by physical adsorption from solution (39, 40 ) or chemical coupling $(41,42)$. We also prepared collagen surfaces by these procedures. In preliminary experiments, the platelet deposition on these collagen surfaces was similar to the deposition on sprayed collagen. More detailed studies are currently in progress.

The platelet deposition on monomeric and fibrillar collagen types I and III were compared (Table IV, Fig. 5). With nonfibrillar collagen on the surface, predominantly single platelets were attached, whereas with fibrillar collagen extensive thrombus formation occurred. Platelet aggregate formation on slides coated with collagen fibrils and exposed to flowing blood was previously reported by Muggli et al. (26). Thrombus formation was also observed when subendothelium was treated with $\alpha$-chymotrypsin to expose collagen fibrils to flowing blood (43).

In order to examine whether and how FVIII-VWF and fibronectin contributed to platelet-collagen interaction, monomeric and fibrillar collagen types I and III were exposed to perfusates with VWD-plasma or fibronectin-free plasma. With both these perfusates, the platelet deposition on nonfibrillar as well as fibrillar collagen was strongly impaired to the low level obtained with HAS (Tables I and V). This indicates that FVIIIVWF and fibronectin are both necessary for optimal platelet adhesion to collagen.

Addition of purified fibronectin to fibronectin-free plasma normalized platelet adhesion. The fibronectin preparations used were purified under either denaturating or nondenaturating 

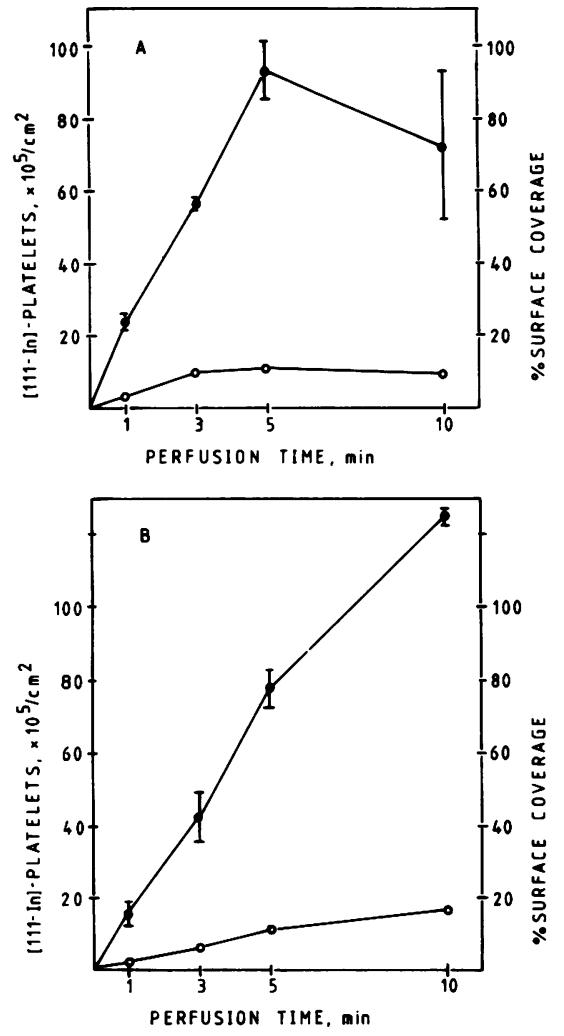

Figure 6. Time course of platelet deposition on fibrillar collagen type I $(A)$ and type III $(B)$ applied at $20 \mu \mathrm{g} / \mathrm{cm}^{2}$. Perfusions were performed with normal plasma at $800 \mathrm{~s}^{-1}$. The total platelet deposition was determined from the ${ }^{111}$ In-radioactivity $(\bullet)$. The percentage surface coverage ( 0 ) was evaluated by en face light microscopy after fixation and staining. Values are mean $\pm \operatorname{SEM}(n=4)$.

conditions. Mosher and Johnson (36) reported on the formation of disulfide bonded multimers with a higher biological activity in certain assays, when concentrated fibronectin solutions were exposed to denaturating agents. With both purification procedures we obtained fibronectin preparations that contained no more than 5\% multimers, and which had the same biological activity in restoring the platelet deposition when added to fibronectin-free plasma (Table II).

The reduced adherence to subendothelium in VWD is shear rate dependent and more pronounced at higher wall shear rates (38). Consistent with this, platelet deposition on

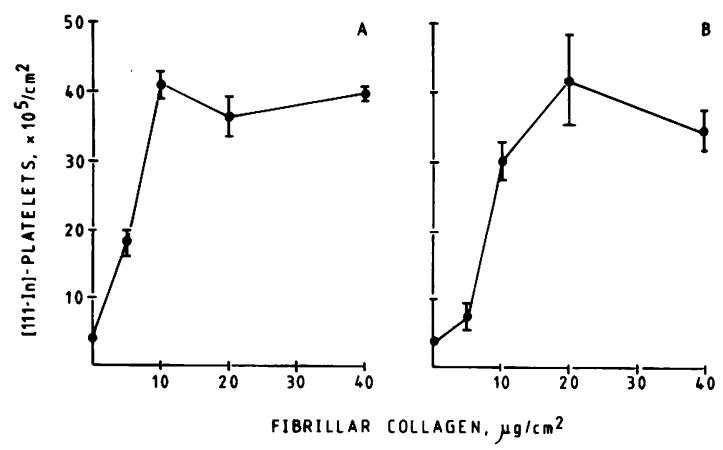

Figure 7. Concentration dependence for platelet deposition on fibrillar collagen type I $(A)$ and type III $(B)$. Perfusions were with normal plasma for 3 min at $800 \mathrm{~s}^{-1}$. Values represent mean $\pm \operatorname{SEM}(n=4)$.
Table V. Platelet Adhesion on Fibrillar Collagen; Influence of Plasma Proteins

\begin{tabular}{|c|c|c|}
\hline \multirow[b]{2}{*}{ Perfusate } & \multicolumn{2}{|c|}{ Platelet adhesion (\% surface coverage) } \\
\hline & Collagen type I & Collagen type III \\
\hline Normal plasma & $7.7 \pm 0.8$ & $5.9 \pm 1.3$ \\
\hline HAS & $<1.0^{*}$ & $<1.0 \ddagger$ \\
\hline VWD-plasma & $1.3 \pm 0.5^{*}$ & $<1.0 \ddagger$ \\
\hline Fibronectin-free plasma & $<1.0^{*}$ & $<1.0 \ddagger$ \\
\hline \multicolumn{3}{|l|}{ Fibronectin-free plasma } \\
\hline+ fibronectin $(300 \mu \mathrm{g} / \mathrm{ml})$ & $7.1 \pm 0.7$ & $3.6 \pm 0.6$ \\
\hline
\end{tabular}

Platelet adhesion on fibrillar collagen types I and III. Preformed fibrils were applied to glass coverslips at $20 \mu \mathrm{g} / \mathrm{cm}^{2}$. Perfusions were performed with the indicated plasmas for $3 \mathrm{~min}$ at $800 \mathrm{~s}^{-1}$. In the case of fibronectin-free plasma, also purified fibronectin was added at a concentration of $300 \mu \mathrm{g} / \mathrm{ml}$. The percentage surface coverage was determined by en face light microscopy after fixation and staining (see Methods). Values are the mean $\pm \operatorname{SEM}(n=4)$. $P$ values are compared with normal plasma.

$* P<0.001$.

$\ddagger P<0.01$.

purified collagen type III also increased with the wall shear rate in normal plasma, but not in VWD-plasma (Fig. 4). In fibronectin-free plasma, platelet deposition was decreased at all shear rates that were tested. Platelets in VWD-plasma exhibit normal aggregation in response to collagen (44). Such platelet aggregation studies are performed at low shear rate,

Table VI. Platelet Adhesion on Fibrillar Collagen Type III; Preincubation with FVIII-VWF and/or Fibronectin

\begin{tabular}{lll}
\hline & & \multicolumn{2}{l}{$\begin{array}{l}\text { Platelet adhesion } \\
\text { Preincubation }\end{array}$} & $\begin{array}{l}\text { \% Surface } \\
\text { coverage }\end{array}$ \\
\hline Buffer & Perfusate & $12.1 \pm 1.6(7)$ \\
& Normal plasma & $<1.0 \quad(8)^{*}$ \\
& HAS & $12.5 \pm 1.6(7)$ \\
& HAS + FVIII-VWF & $<1.0 \quad(8)^{*}$ \\
FVIII-VWF & HAS + FN & $14.7 \pm 2.0(7)$ \\
& HAS + FN + FVIII-VWF & $18.4 \pm 3.0(7)$ \\
FN & HAS & $18.5 \pm 3.2(7)$ \\
& HAS + FN & $<1.0 \quad(8)^{*}$ \\
FN + FVIII-VWF & HAS & $16.3 \pm 2.4(8)$ \\
& HAS + FVIII-VWF & $13.9 \pm 2.0(6)$
\end{tabular}

Fibrillar collagen type III $\left(20 \mu \mathrm{g} / \mathrm{cm}^{2}\right)$ was preincubated with FVIIIVWF $(1 \mathrm{U} / \mathrm{ml})$ and/or fibronectin $(200 \mu \mathrm{g} / \mathrm{ml})$ or buffer only for 30 $\mathrm{min}$ at room temperature. Perfusions were performed for $3 \mathrm{~min}$ at $1,300 \mathrm{~s}^{-1}$ with platelets in HAS. The HAS perfusates were supplemented with FVIII-VWF $(1 \mathrm{U} / \mathrm{ml})$ or fibronectin $(200 \mu \mathrm{g} / \mathrm{ml})$ or both. After the perfusions, the coverslips were fixed and stained and the percentage surface coverage determined by en face morphometrical evaluation. The values represent the mean \pm SEM with the number of determinations in parentheses. $P$-Values are compared with normal plasma. FN, fibronectin.

$* P<0.001$ 
Table VII. Platelet Adhesion on Fibrillar Collagen Type III; Effect of FVIII-VWF and Fibronectin in Plasma

\begin{tabular}{lc}
\hline & \multicolumn{1}{c}{ Platelet adhesion } \\
\cline { 2 - 2 } Perfusate & \% Surface coverage \\
\hline Normal plasma & $7.6 \pm 0.5$ \\
Fibronectin-free VWD-plasma & $<1.0^{*}$ \\
+ FVIII-VWF & $3.3 \pm 1.9 \ddagger$ \\
+ FN & $<1.0^{*}$ \\
+ FVIII-VWF + FN & $11.7 \pm 2.8$
\end{tabular}

Coverslips were coated with fibrillar collagen type III, $20 \mu \mathrm{g} / \mathrm{cm}^{2}$. Perfusions were performed for $3 \mathrm{~min}$ at $1,300 \mathrm{~s}^{-1}$. VWD-plasma (FVIIIR:RCF $<0.06 \mathrm{U} / \mathrm{ml}$ ) was depleted of fibronectin by gelatin-Sepharose affinity chromatography. This fibronectin-free VWD-plasma was supplemented with either purified FVIII-VWF $(1 \mathrm{U} / \mathrm{ml})$ or fibronectin $(200 \mu \mathrm{g} / \mathrm{ml})$ or both. Values are mean \pm SEM $(n=4)$. $P$-Values are compared with normal plasma. FN, fibronectin.

$* P<0.01$.

$\ddagger P<0.05$.

where there is no requirement for FVIII-VWF, as is also evident from our results. Platelet aggregation in response to collagen has also no requirement for fibronectin. Fibronectin may even inhibit platelet aggregation by collagen (12). In contrast to this, we still found a requirement for fibronectin at $490 \mathrm{~s}^{-1}$, the lowest shear rate tested here. The requirement at yet lower wall shear rates is currently under investigation.

The finding that optimal deposition on collagen types I and III is mediated by FVIII-VWF and fibronectin was further substantiated by experiments in which nonfibrillar collagen types I and III were preincubated with these proteins (Table III). The adsorption of FVIII-VWF to different collagen types has been reported $(45,46)$. Fibronectin also binds to the various collagen types (17), and the binding site on collagen type I has been identified $(47,48)$. The collagen-binding site on fibronectin is also known (49). Preincubation of both collagen types with first FVIII-VWF and then fibronectin or preincubation with these proteins in reverse order showed a similar platelet deposition. The absence of a preferred order in the adsorption to collagen makes it unlikely that FVIIIVWF binds to collagen via fibronectin, or the reverse. Recent data from endothelial cell culture studies have suggested that a direct interaction occurs between FVIII-VWF and fibronectin because these proteins codistributed in the subendothelial matrix (50). Our data do not rule out such interaction, but they indicate that both FVIII-VWF and fibronectin from plasma interact directly with collagen and are then able to support platelet adhesion.

These preincubation experiments were also performed with fibrillar collagen type III (Table VI). In contrast to nonfibrillar collagen, there was only a requirement for FVIII-VWF and not for fibronectin. These results were obtained when perfusions were performed with HAS, but when plasma was used there was a dependence on both proteins, as is evident from Tables V and VII. These data seem contradictory, but the possibility exists that the platelets are activated by fibrillar collagen and release fibronectin from the $\alpha$-granules (37). This released fibronectin can bind to the platelet membrane (51) or to collagen (52), and support platelet adhesion in HAS. In fibronectin-free plasma, platelet adhesion is not supported by released fibronectin, possibly because of competition with other plasma proteins.

Fibronectin is known to be involved in the attachment and spreading of many cell types on collagen substrata (53). The involvement of fibronectin in the adhesion of platelets to collagen was first suggested by Hynes et al. (54). Later, several investigators have observed that fibronectin may promote the spreading of platelets on collagen-coated surfaces $(9,10)$. Bensusan et al. (8) has proposed that fibronectin on the surface of platelets acts as the receptor for collagen, but this has not been confirmed by others (11). Platelets contain fibronectin in their $\alpha$-granules and release it upon stimulation with thrombin or collagen (37). After activation, saturable binding of fibronectin to the platelet membrane occurs (51). These results suggest a possible role for fibronectin in platelet-collagen interaction. Booyse et al. (55) has reported on the effect of porcine plasma and FVIII-VWF and human fibronectin on the interaction of porcine platelets with culture-produced subendothelium. The combined action of FVIII-VWF and fibronectin was required for maximal platelet-subendothelium interaction and spreading. A possible role for fibronectin as a spreading factor was suggested. From the data presented here it is clear that for optimal platelet interaction with collagen in flowing blood both FVIII-VWF and fibronectin are required.

The absence of a requirement for fibronectin and FVIIIVWF in inducing platelet aggregation by collagen and the implication of FVIII-VWF and fibronectin as spreading factors together with our data here lead to the following working hypothesis. The initial interaction of platelets with collagen has no requirement for other proteins, but the spreading of platelets on the collagen surface is not optimal. Platelets will thus remain attached at low shear rates but not at high shear rates. Fibronectin may enhance spreading sufficiently to let platelets remain attached at intermediate shear rates. Another protein, FVIII-VWF, is required at high shear rates to give the enhanced spreading for platelets to remain attached (6). The role for FVIII-VWF as a spreading factor on subendothelium at high shear rates was recently disputed by Turitto et al. (56), who implicated a role for FVIII-VWF in the initial contact phase. Studies with collagen-coated slides recently implicated FVIII-VWF in both initial attachment and spreading (57).

Whatever the exact mechanism of platelet attachment to collagen, FVIII-VWF and fibronectin are clearly involved. The attachment site for platelets on collagen is probably a mosaic of fibronectin and FVIII-VWF molecules together with binding sites to collagen itself, which ensures a tight junction with the platelet membrane.

\section{Acknowledgments}

We thank Dr. T. van den Bos, State University of Utrecht, Department of Dentistry, for help in the isolation of collagen. The technical assistance of Mrs. M. Ottenhof-Rovers is gratefully acknowledged.

This study was supported by the Foundation for Medical Research (FUNGO) grant 13-30-92.

\section{References}

1. Sixma, J. J., and J. Wester. 1977. The hemostatic plug. Semin. Hematol. XIV:265-299. 
2. Hovig, T., and H. Stormorken. 1974. Ultrastructural studies on the platelet plug formation in bleeding time wounds from normal individuals and patients with von Willebrand's disease. Acta Pathol. Microbiol. Scand. 248(Suppl.):105-122.

3. Tschopp, T. B., H. J. Weiss, and H. R. Baumgartner. 1974. Decreased adhesion of platelets to subendothelium in von Willebrand's disease. J. Lab. Clin. Med. 83:296-300.

4. Weiss, H. J., H. R. Baumgartner, T. B. Tschopp, V. T. Turitto, and D. Cohen. 1978. Correction by Factor VIII of the impaired platelet adhesion to subendothelium in von Willebrand's disease. Blood. 51:267279.

5. Sakariassen, K. S., P. A. Bolhuis, and J. J. Sixma. 1979. Human blood platelet adhesion to artery subendothelium is mediated by factor VIII-von Willebrand factor bound to the subendothelium. Nature (Lond.). 279:635-638.

6. Bolhuis, P. A., K. S. Sakariassen, H. J. Sander, B. N. Bouma, and J. J. Sixma. 1981. Binding of factor VIII-von Willebrand factor to human arterial subendothelium precedes increased platelet adhesion and enhances platelet spreading. J. Lab. Clin. Med. 97:568-576.

7. Baumgartner, H. R., T. B. Tschopp, and H. J. Weiss. 1977. Platelet interaction with collagen fibrils in flowing blood. II. Impaired adhesion-aggregation in bleeding disorders. A comparison with subendothelium. Thromb. Haemostasis. 37:17-28.

8. Bensusan, H. B., T. L. Koh, K. G. Henry, B. A. Murray, and L. A. Culp. 1978. Evidence that fibronectin is the collagen receptor on platelet membranes. Proc. Natl. Acad. Sci. USA. 75:5864-5868.

9. Grinnell, F., M. Feld, and W. Snell. 1979. The influence of cold insoluble globulin on platelet morphological response to substrata. Cell Biol. Int. Reports. 3:585-592.

10. Koteliansky, V. E., V. L. Leytin, D. D. Sviridov, V. S. Repin, and V. N. Smirnov. 1981. Human plasma fibronectin promotes the adhesion and spreading of platelets on surfaces coated with fibrillar collagen. Febs (Fed. Eur. Biochem. Soc.) Lett. 123:59-62.

11. Santoro, S. A., and L. W. Cunningham. 1979. Fibronectin and the multiple interaction model for platelet-collagen interaction. Proc. Natl. Acad. Sci. USA. 76:2644-2648.

12. Sochynsky, R. A., B. J. Boughton, J. Burns, B. C. Sykes, and J. O. D. McGee. 1980. The effect of human fibronectin on plateletcollagen adhesion. Thromb. Res. 18:521-533.

13. Chung, E., and E. J. Miller. 1974. Collagen polymorphism: characterization of molecules with the chain composition $\left(\alpha_{1}(\mathrm{III})\right)_{3}$ in human tissues. Science (Wash. DC). 183:1200-1201.

14. ChandraRajan, J. 1978. Separation of type III collagen from type I collagen and pepsin by differential denaturation and renaturation. Biochem. Biophys. Res. Commun. 83:180-186.

15. Bruns, R. R., and J. Gross. 1977. High resolution analysis of the quarter stagger model of the collagen fibril. Biopolymers. 13:931941.

16. Williams, B. R., R. A. Gelman, D. C. Poppke, and K. A. Piez. 1978. Collagen fibril formation. Optimal in vitro conditions and preliminary kinetic results. J. Biol. Chem. 253:6578-6585.

17. Engvall, E., E. Ruoslahti, and E. J. Miller. 1978. Affinity of fibronectin to collagens of different genetic types and to fibrinogen. $J$. Exp. Med. 147:1584-1595.

18. Laurell, C. B. 1972. Electro-immunoassay. Scand. J. Clin. Lab. Invest. 29(Suppl.):21-37.

19. Klebe, R. J., K. L. Bentley, P. J. Sasser, and R. C. Schoen. 1980. Elution of fibronectin from collagen with chaotropic agents. Exp. Cell Res. 130:111-117.

20. Vuento, M., and A. Vaheri. 1979. Purification of fibronectin from human plasma by affinity chromatography under non-denaturating conditions. Biochem. J. 183:331-337.

21. Cejka, J. 1982. Enzyme immunoassay for factor VIII-related antigen. Clin. Chem. 28:1356-1358.

22. Amrani, D. L., G. A. Homandberg, N. M. Tooney, C. Wolfenstein-Todel, and M. W. Mosesson. 1983. Separation and analysis of the major forms of plasma fibronectin. Biochim. Biophys. Acta. 748:308-320.
23. Van Mourik, J. A., and I. A. Mochtar. 1970. Purification of human antihemophilic factor (Factor VIII) by gelchromatography. Biochim. Biophys. Acta. 221:677-679.

24. Over, J., J. J. Sixma, M. H. M. Doucet-de Bruine, A. M. C. Trieschnigg, R. A. Vlooswijk, N. H. Beeser-Visser, and B. N. Bouma. 1978. Survival of ${ }^{125}$ Iodine-labeled Factor VIII in normals and patients with classic hemophilia. Observations on the heterogeneity of human factor VIII. J. Clin. Invest. 62:223-234.

25. Sakariassen, K. S., P. A. M. M. Aarts, P. G. de Groot, W. P. M. Houdijk, and J. J. Sixma. 1983. A perfusion chamber developed to investigate platelet interaction in flowing blood with human vessel wall cells, their extracellular matrix, and purified components. J. Lab. Clin. Med. 102:522-535.

26. Muggli, R., H. R. Baumgartner, T. B. Tschopp, and H. Keller. 1980. Automated microdensitometry and protein assay as a measure for platelet adhesion and aggregation on collagen-coated slides under controlled flow conditions. J. Lab. Clin. Med. 95:195-207.

27. Heyns, A. du P., P. N. Badenhorst, H. Pieters, M. G. Lötter, P. C. Minnaar, L. J. Duyvené de Wit, O. R. van Reenen, and F. P. Retief. 1980. Preparation of a viable population of Indium-111-labeled human blood platelets. Thromb. Haemostasis. 42:1473-1482.

28. Baumgartner, H. R., and R. Muggli. 1976. Adhesion and aggregation: morphological demonstration and quantitation in vivo and in vitro. In Platelets in Biology and Pathology. J. Gordon, editor. North-Holland Publishing Co., Amsterdam. 23-60.

29. Sakariassen, K. S., P. A. Bolhuis, and J. J. Sixma. 1980. Platelet adherence to subendothelium of human arteries in pulsatile and steady flow. Thromb. Res. 19:547-559.

30. Bradford, M. M. 1976. A rapid and sensitive method for the quantitation of microgram quantities of protein utilizing the principle of protein-dye binding. Anal. Biochem. 72:248-254.

31. Stegemann, H., and K. Stalder. 1967. Determination of hydroxyproline. Clin. Chim. Acta. 18:267-273.

32. Szymanowicz, A. G., G. Bellon, G. Laurain-Guillaume, T. Delvincourt, A. Randoux, T. Caulet, and J. P. Borel. 1982. An evaluation by sequential extraction of the proportions of collagen types from medium sized arteries. Artery. 10:250-265.

33. Allain, J. P., H. A. Cooper, R. H. Wagner, and K. M. Brinkhous. 1975. Platelets fixed with paraformaldehyde: a new reagent for assay of von Willebrand factor and platelet aggregating factor. $J$. Lab. Clin. Med. 85:318-328.

34. Macfarlane, D. E., J. Stibbe, E. P. Kirby, M. B. Zucker, R. A. Grant, and J. McPherson. 1975. A method for assaying von Willebrand factor (ristocetin cofactor). Thromb. Diath. Haemorrh. 34:306-308.

35. Laemmli, U. K. 1970. Cleavage of structural proteins during the assembly of the head of bacteriophage T4. Nature (Lond.). 227:680685 .

36. Mosher, D. F., and R. B. Johnson. 1983. In vitro formation of disulfide-bonded fibronectin multimers. J. Biol. Chem. 258:6595-6601.

37. Zucker, M. B., M. W. Mosesson, M. J. Broekman, and K. L. Kaplan. 1979. Release of platelet fibronectin (cold-insoluble globulin) from alpha granules induced by thrombin or collagen; lack of requirement for plasma fibronectin in ADP-induced platelet aggregation. Blood. 54:8-12.

38. Weiss, H. J., V. T. Turitto, and H. R. Baumgartner. 1978. Effect of shear rate on platelet interaction with subendothelium in citrated and native blood. I. Shear rate-dependent decrease of adhesion in von Willebrand's disease and the Bernard-Soulier syndrome. J. Lab. Clin. Med. 92:750-764.

39. Penners, G., Z. Priel, and A. Silberberg. 1981. Irreversible adsorption of triple-helical soluble collagen monomers from solution to glass and other surfaces. J. Colloid Interface Sci. 80:437-444.

40. Silberberg, A., and J. Klein. 1981. Structure and properties of surface adsorbed biopolymer layer. Soluble collagen adsorbed to glass. Biorheology. 18:589-599.

41. Aplin, J. D., and R. C. Hughes. 1981. Protein-derivatised glass coverslips for the study of cell-to-substratum adhesion. Anal. Biochem. 113:144-148. 
42. Shadle, P. J., and S. H. Barondes. 1982. Adhesion of human platelets to immobilized trimeric collagen. J. Cell. Biol. 95:361-365.

43. Baumgartner, H. R. 1977. Platelet interaction with collagen fibrils in flowing blood. I. Reaction of human platelets with $\alpha$-chymotrypsindigested subendothelium. Thromb. Haemostasis. 37:1-16.

44. Weiss, H. J. 1970. Aspirin ingestion compared with bleeding disorders. Search for a useful platelet antiaggregant. Blood. 35:333340.

45. Legrand, Y. J., A. Rodriguez-Zeballos, G. Kartalis, F. Fauvel, and J. P. Caen. 1978. Adsorption of factor VIII antigen-activity complex by collagen. Thromb. Res. 13:909-911.

46. Santoro, S. A. 1981. Adsorption of von Willebrand factor/ factor VIII by the genetically distinct interstitial collagens. Thromb. Res. 21:689-693.

47. Kleinman, H. K., E. B. McGoodwin, G. R. Martin, R. J. Klebe, P. P. Fietzek, and D. E. Woolley. 1978. Localization of the binding site for cell attachment in the $\alpha_{1}$ (I) chain of collagen. J. Biol. Chem. 253:5662-5646.

48. Dessau, W., B. C. Adelman, R. Timpl, and G. R. Martin. 1978. Identification of the sites in collagen $\alpha$-chains that bind serum anti-gelatin factor (cold insoluble globulin). Biochem. J. 169:55-59.

49. Balian, G., E. M. Glick, and P. Bornstein. 1980. Location of a collagen binding domain in fibronectin. J. Biol. Chem. 255:32343236.

50. Wagner, D. D., M. Urban-Pickering, and V. J. Marder. 1984. Von Willebrand protein binds to extracellular matrices independently of collagen. Proc. Natl. Acad. Sci. USA. 81:471-475.
51. Plow, E. F., and M. H. Ginsberg. 1981. Specific and saturable binding of plasma fibronectin to thrombin stimulated platelets. J. Biol. Chem. 256:9477-9482.

52. Lahav, J., M. A. Alexander, and R. O. Hynes. 1982. Analysis of platelet adhesion with a radioactive chemical cross-linking reagent: interaction of thrombospondin with fibronectin and collagen. Cell. 31:253-262.

53. Kleinman, H. K., R. J. Klebe, and G. R. Martin. 1981. Role of collagenous matrices in the adhesion and growth of cells. J. Cell Biol. 88:473-485.

54. Hynes, R. O., I. U. Ali, A. T. Destree, V. M. Mautner, M. E. Perkins, D. R. Senger, D. D. Wagner, and K. K. Smith. 1978. A large glycoprotein lost from the surface of transformed cells. Ann. NY Acad. Sci. 312:317-342.

55. Booyse, F. M., S. Feder, and A. J. Quarfoot. 1982. Cultureproduced subendothelium. II. Effect of plasma, FVIII R:WF and fibronectin on interaction of normal platelets with normal and von Willebrand porcine aortic subendothelium. Thromb. Res. 28:299-311.

56. Turitto, V. T., H. J. Weiss, and H. R. Baumgartner. 1983. Decreased platelet adhesion on vessel segments in von Willebrand's disease: a defect in initial platelet attachment. J. Lab. Clin. Med. 102:551-564.

57. Leytin, V. L., N. A. Gorbunova, F. Misselwitz, I. D. Novikov, E. A. Podrez, O. P. Plyusch, E. A. Likhachova, V. S. Repin, and V. N. Smirnov. 1984. Step-by-step analysis of adhesion of human platelets to a collagen-coated surface. Defect in initial attachment and spreading of platelets in von Willebrand's disease. Thromb. Res. 34:5163. 